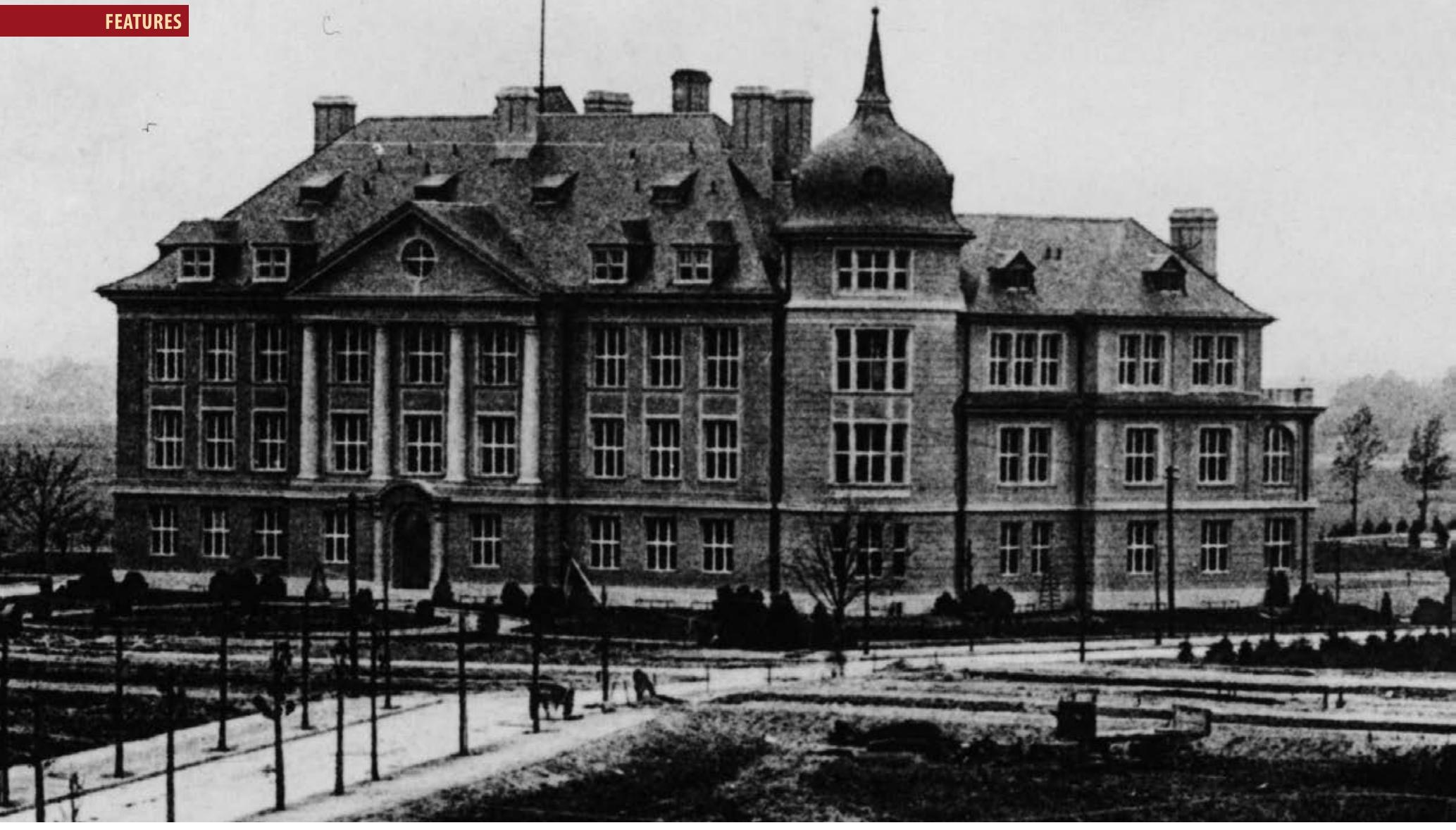

\title{
A TRIBUTE TO
}

LISE MEITNER (1878-1968)

• Henk Kubbinga - University of Groningen (The Netherlands) - DOI: https://doi.org/10.1051/epn/2019402

Physics is irresistible. Though prepared to become a teacher of French at an Austrian highschool, Lise Meitner, daughter of a lawyer, could not help coming under the spell of physics. By lucky coincidence she followed courses dispensed by no one less than Ludwig Boltzmann, whose wit and humour proved contagious. After her PhD, under Franz Exner, she moved on, not to Paris to work with Marie Curie, but to Berlin, to consult with Max Planck on future contingencies. Before leaving for Berlin, however, she was introduced to 'radioactivity' by Stefan Meyer.

$\triangle$ The Kaiser

Wilhelm Institute

for Chemistry,

Berlin-Dahlem (courtesy: Archives of the Max-PlanckGesellschaft, Berlin).

\section{Radioactivity anno 1905; Vienna}

The supposed Röntgen-rays produced by uranyl, a uranium salt, had been identified by Marie Curie Skłodowska (1897-1898) to be an entirely new kind of spontaneous radiation by minerals, one that could be blocked by heaps of aluminium foil-sheets. In fact there were two kinds at stake: one of these radiations needed but a few sheets, the other several more. Rutherford called them $\alpha$ - and $\beta$-rays, respectively. So much was sure: it was an atomic effect and new, extremely active, elements were in the game ( $\mathrm{Po}, \mathrm{Ra})$. Moreover, there were huge amounts of energy involved. Thorium minerals appeared to be even more 'radioactive' than pure uranium. Rutherford also noticed the material nature of part of the radiation: a current of air, caused by an open door, was enough to disturb the discharging of an electroscope. Were atoms a kind of 'polymers' of $\alpha$-particles and 'radioactivity' a matter of 'depolymerisation' or was it, more generally, a kind of 'disintegration' ? 
These were the hot topics anno 1905. Though thrilled by Boltzmann's towering personality, his students in Vienna, among whom one Lise Meitner, did not learn much on the novelties. Meitner, though, heard of 'radioactivity' through Stefan Meyer, an assistant of Boltzmann. Following her PhD-under Franz Exner-on heat conductivity in inhomogeneous media, in February 1906, Meitner opted for the new field; already in July 1906 appeared her first singly-authored paper on the absorption of $\alpha$ - and $\beta$-rays [1]. Another paper, one on the absorption and/or dispersion of $\alpha$-rays by sheafs of various metal foils (Ag, $\mathrm{Cu}, \mathrm{Pt}$ and Sn), followed in 1907 and brought her to settle a matter which opposed Ernest Rutherford, on the one hand, and Bohumil Kučera and Bohuslav Mašek, on the other, to William H. Bragg. Accidentally, Meitner made the acquaintance of Max Planck, on visit in Vienna as a candidate to succeed to Boltzmann.

\section{From Vienna to Berlin (1907); Otto Hahn}

'Radioactivity' was the topic of the day, not-not yet-quanta or photons. The place to be was either Paris, London, Berlin, or Prague. With dreams of an Austria united to Germany, Meitner opted for Berlin. She inquired with the generally beloved Planck, who had been nominated as the new editor-in-chief of the Annalen der Physik and who, though not a shadow of the spirited Boltzmann, taught Theoretical Physics. With her taste for experimental work, she also approached Heinrich Rubens. Again no problem: she got a place in his laboratory and enrolled for the Physics Colloquium. A charming lad, one Otto Hahn, a radiochemist who had just returned from a trip to Ramsay (London) and Rutherford (Montreal), used to be there, too. Hahn was already an authority in the field, but couldn't help remaining a drop-out among the Berlin chemists. A livelong comradeship in science was born.

Meitner and Hahn opted for a study of $\beta$-rays, first through their absorption and/or dispersion behaviour, later through their curvature in magnetic fields (Fig.2). The identity of these rays with those of the discharge tube appeared i.a. by letting a flat beam graze over a perpendicular screen covered with fluorescent material: by applying a magnetic field the beam curved indeed (Fig.3).What is more, the initial beam split up, suggesting the presence of particles of discrete velocities, and hence different sources (Fig.3 and 4). In 1912 Hahn and Meitner came to focus on the actinium-series, where a mysterious sequence of $\alpha$ - and $\beta$-emitters seemed to hint at an as yet unknown precursor. Atomic and nuclear physics were booming: Soddy coined the notion 'isotope', Moseley revealed the role of the nuclear charge in a RutherfordBohr kind of atom. The 'replacement laws' were formulated: release of an $\alpha$-particle implied the production of an element two places backwards at the Periodic Table, release of a $\beta$-particle of an element one place forwards.
The Great War changed a lot: all over Europe young scientists, like any other section of the population, enthusiastically joined the various armies. Hope was in the air, on all sides, though science suffered. Marie Curie and her Irène organized the Röntgen-Department of the French army, Meitner came to do something similar on the German-Austrian side. From time to time she returned to Berlin to continue the elucidation of the actinium series, in sustained correspondence with Otto Hahn; Hahn himself also showed up every now and then. In the case of actinium it struck that it was only found in $\mathrm{U}$-ores, that is, in any $\mathrm{U}$-ore whatsoever, and so in a small though constant proportion. Actinium's half-life was estimated at 30 years, which implied that it could impossibly be the first term of a series, let's say, like U. The conclusion imposed itself that actinium and its derivatives represented a branching off from the already well-known U-series and that there should exist another species serving to bridge the gap between $U$ and Ac. With the Periodic Table at hand a possible route to Ac could be designed: knowing that $\alpha$-active $U$ features in Group VI, it was clear that its derivative belonged to Group IV, had valency 4 and ought to be, therefore, an isotope of thorium. There were two candidates: 'ionium, the $\alpha$-active mothersubstance of radium, and a $\beta$-active isotope, the two produced in the ratio of $97: 3$. Actinium, then, should

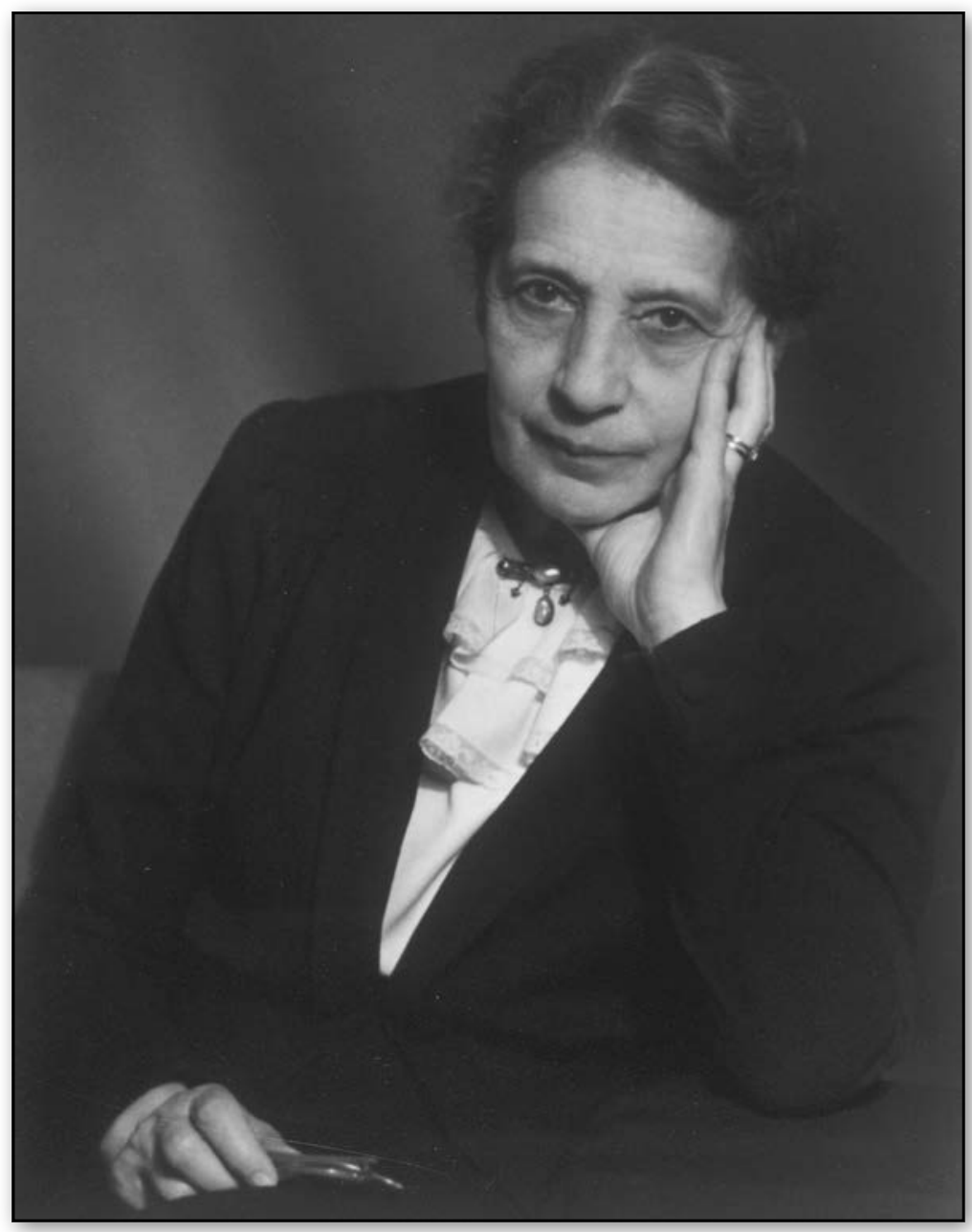

v FIG. 1: Lise Meitner (1947) by her sisterGraf (courtesy: National Library of Austria, Vienna). in-law, Lotte Meitner- 
be related to that $\beta$-active Th-isotope. Since actinium's chemistry had shown that it belonged to Group III, that of lanthanum, it was clear that it derived from a bivalent $\beta$-emitter or a pentavalent $\alpha$-emitter. The only bivalent candidate was $\alpha$-active $\mathrm{Ra}$, so the choice to be made was for the other, the pentavalent species, similar to tantalum. It was this line of reasoning which led to the identification of the new element, which was baptized, in a paper coauthored with Hahn,'protactinium' [4]. By then, Meitner headed, as Professor, the newly created Physics Section of the Kaiser-Wilhelm Institute for Chemistry and went her own way, at least for a while.

\section{The neutron and its transuranium promises $(1919,1932)$}

In 1919 Rutherford had directed a source of $\alpha$-particles at nitrogen gas when he noticed the appearance of flashes upon a ZnS-screen far beyond the range of the $\alpha$-particles themselves. Highly energetic lighter particles were in the game, provisionally called 'protons'. Obviously, some of the $\mathrm{N}$-atoms had been affected in the process, a case of an artificially induced nuclear reaction. It was not yet clear how, precisely: were there two or three particles produced ? The cloud chamber, then, showed that there were just two tracks, suggesting that the He-nucleus was absorbed, the 'proton' being expelled:

$$
\mathrm{N}_{7}^{14}+\mathrm{He}_{2}^{4} \rightarrow \mathrm{O}_{8}^{17}+\mathrm{H}_{1}^{1}
$$

Rutherford, then, adapted his earliest hypothesis, taking nuclei now as clusters of $\alpha$-particles and free 'protons'; $\beta$-particles were indispensable, if only to account for the required charge. Hence Rutherford's idea of a neutral particle consisting of a proton and an electron; he called it a 'neutron'. Through the eyes of Meitner-it is 1921this implied that she could write down the nuclei of the successive elements of the Periodic Table and their isotopes, and foretell approximately how an eventual reaction would proceed on bombarding them with $\alpha$ or $\beta$-particles. For instance, a classic, the $\mathrm{U}_{92}^{238}$-nucleus, could be considered as a whole of $46 \alpha$-particles, $13 \mathrm{He}$ atoms, $2 \mathrm{H}$-ions and 2 free electrons, in Meitner's notation written as follows:

$$
46 \alpha+13\left(\alpha^{\prime}+2 \beta\right)+2 \mathrm{H}^{\cdot}+2 \mathrm{e}
$$

Conversely, it was possible to predict the existence of as yet unknown moieties. In order to further study the variables of such experiments she devised a cloud chamber of her own and measured the effects of condensable vapours other than water and those of other carrier gases than air (1924). The $\gamma$-rays typical for $\beta$-decay puzzled her: they might originate from $\beta$-particles transformed into energy, as she thought initially, or come from energy transitions in the nucleus. On leaving the nucleus they caused at any rate an internal photo-electrical effect, causing the continuous $\beta$-spectrum as observed most of the time.

Following the identification of the 'neutron' and the discovery of the 'positron' and the 'deuteron', the $7^{\text {th }}$ Solvay Conference on Physics came to be devoted to the structure and properties of nuclei; it was convened at Brussels in October 1933, with Meitner (and Fermi) among the invited guests. Bombarding uranium with 'neutrons', produced by Po- $\alpha$-particles hitting a Be-target, seemed the natural way to create isotopes eventually featuring $\beta$-decay leading to new elements, heavier than uranium. Fermi and his team claimed, in May 1934, to have found two such 'transuranes'. Meitner was on top of all this, naturally. As the expert in the field she was also key-note at the Mendeleev centenary in Leningrad, on 11 September 1934, with a lecture on the relation between nuclei and the Periodic Table. Back home, she

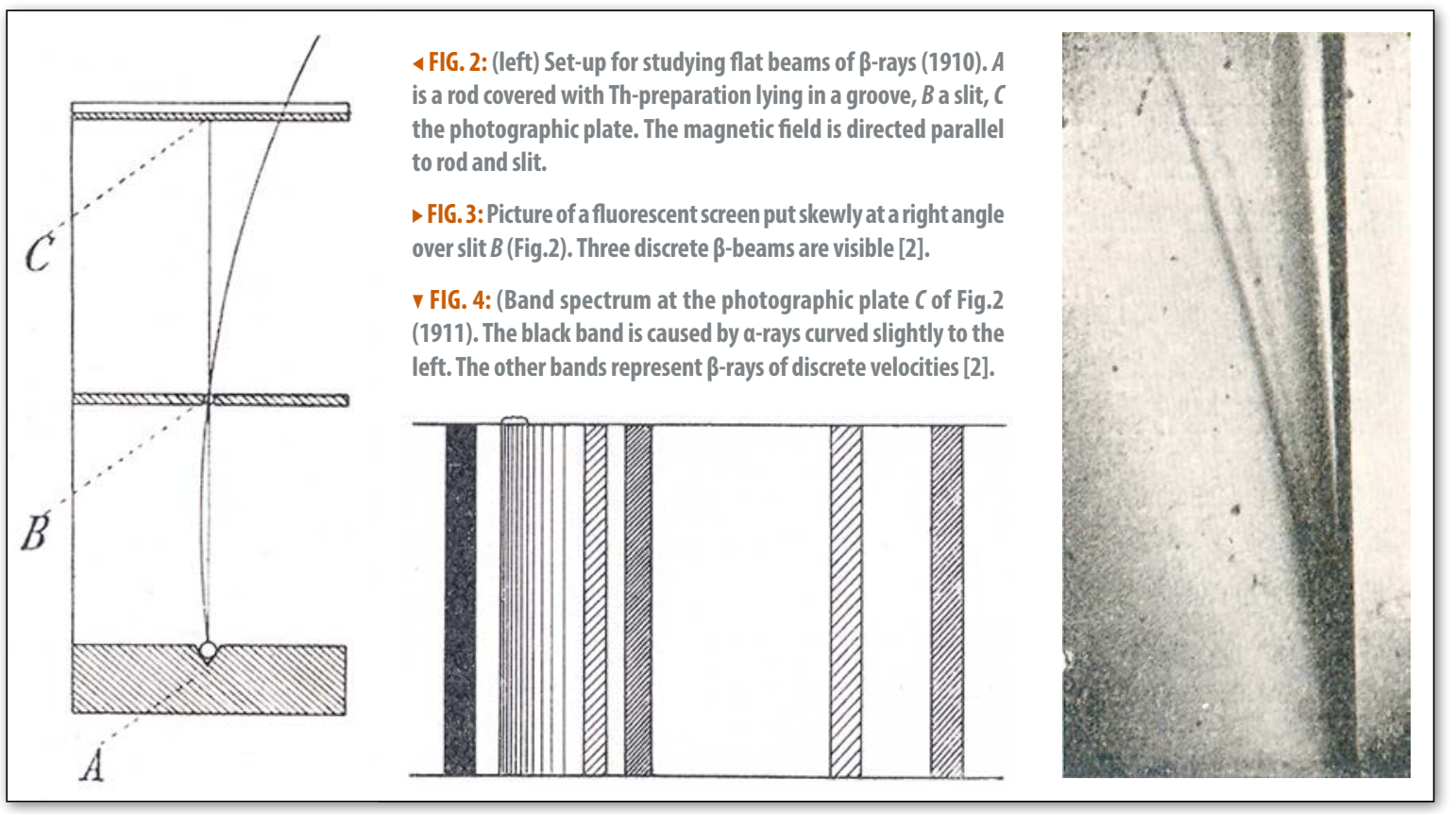




\section{PFEIFFER VACUUM}
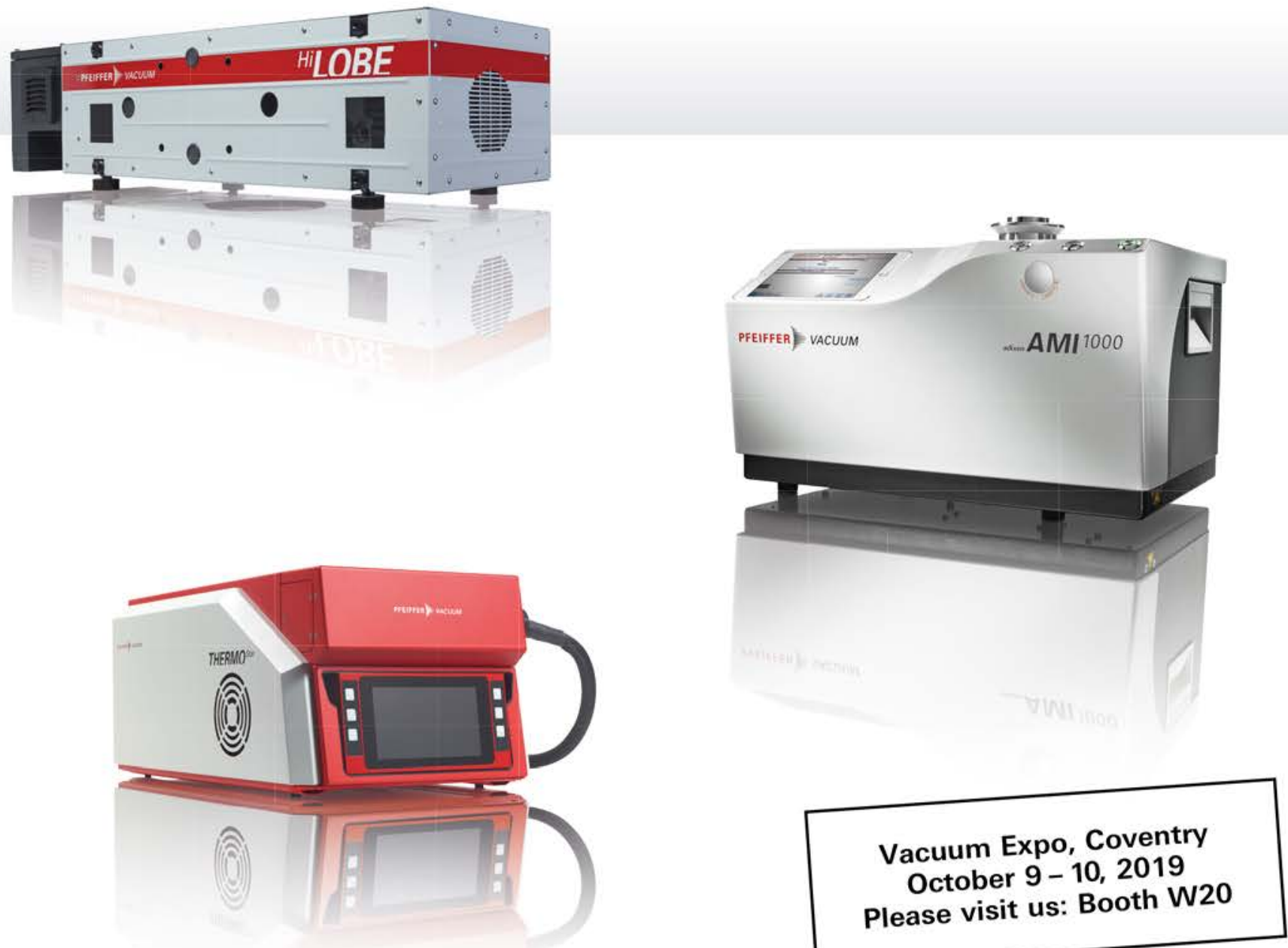

\section{PFEIFFER VACUUM - YOUR PARTNER FOR VACUUM SOLUTIONS}

Discover how our latest technological innovations for generating and monitoring vacuum, and for detecting leaks, can help you optimize your vacuum process. We are the only supplier of vacuum technology that provides a complete product portfolio:

- Pumps for vacuum generation down to UHV

- Vacuum measurement and analysis equipment

- Leak detectors and integrity test systems

- Chambers and components 


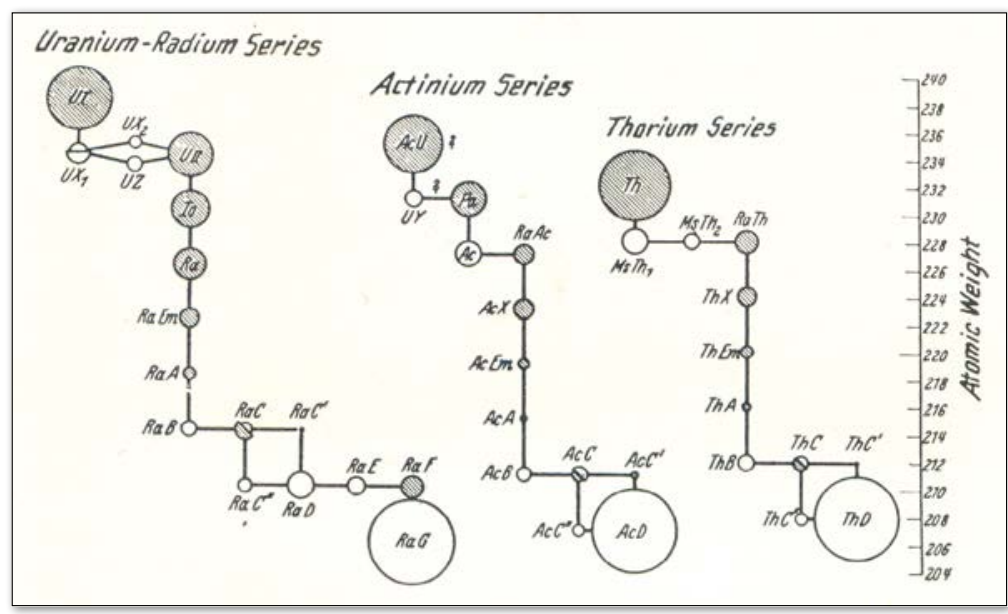

$\triangle$ FIG. 5: The three disintegration series anno 1936 [3]. The radii of the circles are a measure for the stability; shaded circles indicate a-radiators, open circles $\beta$-radiators. On the right we see 'atomic weight' ('mass number')

v FIG. 6: Titlepage of Dirk Coster's private copy of Lise Meitner and Max Delbruck's monograph DerAufbau der Atomkerne [5].

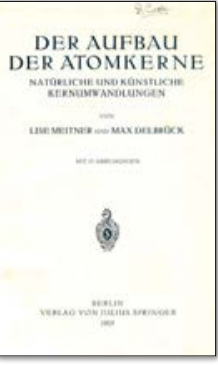

decided to rework her talk into a review-like booklet; Max Delbrück, a post-doc, signed for the theoretical part (Fig.6). Stability, we read there, e.g. that of the Henucleus, was a crucial notion, to be defined in terms of the mass-defect. And also: $\beta$-particles and the newly discovered positrons did not exist as such in the nucleus their production revealed interconversions of protons and neutrons. Hahn and Meitner, in touch with Fermi and the Joliot-Curies, decided to see if they, too, could bring about artificial radioactivity and confirm in one way or another the existence of transuranes.

\section{Joining forces, again;} nuclear fission (1938/39)

Bombarding the $\mathrm{U}_{92}^{238}$-nucleus with neutrons produced about nine $\beta$-activities, among which doubtless one or more transuranes or eka-homologs of the elements $\mathrm{Re}, \mathrm{Os}, \mathrm{Ir}, \mathrm{Pt}$ and $\mathrm{Au}$ :

$$
\mathrm{U}_{92}^{238}+n_{0}^{1} \rightarrow\left[\mathrm{U}_{92}^{238}+n_{0}^{1}\right] \rightarrow \beta \text {-decays }
$$

Hahn, Meitner and their collaborator Strassmann considered three parallel $\beta$-decay series involving nuclear 'isomers', something new and imperative, if only to account for the numbers. The chemical separation proved puzzling all the same: when all the presumed transuranes precipitated as low soluble sulphides by adding $\mathrm{H}_{2} \mathrm{~S}$ to an $\mathrm{HCl}$-solution, there remained an activity in the liquid, which behaved as if a Ra-isotope was at stake, since it coprecipitated with $\mathrm{Ba}$-salt, a standard procedure with $\mathrm{Ra}$. A further separation failed, however: was the presumed Ra nothing but $\mathrm{Ba}$ ? In the week before Christmas 1938 Hahn informed Meitner, by now in Stockholm, on the estranging finds: uranium producing barium, how could that be ? Meitner was shocked, but, as she wrote by return mail, nuclear physics had already caused more 'impossible' surprises. On reconsidering Hahn's results, together with her nephew Otto Frisch on vacation in Stockholm, she concluded that apart from barium $(\mathrm{Z}=56)$ the uranium had produced xenon $(\mathrm{Z}=36)$ and that huge amounts of energy were at stake. Nuclear 'fission' got its name. It appeared to be a 'classical' process in that the nucleus behaved like a droplet of a liquid, with shape variations which could be overagitated by neutron capture, bringing about the observed splitting up into two highly repulsive parts. The eka- 'isomers' of before became various $\mathrm{Ba}$ - and $\mathrm{Xe}$-isotopes, depending on the neutron numbers, each with a decay period of its own.

If the grandeur of Meitner and Hahn is in their epochal partnership, the petitesse was brought by history. On leaving Berlin for Groningen with Dirk Coster, that Wednesday, July $13^{\text {th }}, 1938$, Meitner received from Hahn the diamond ring of his mother to help her overcome eventual formalities. During the blood-curdling voyage Meitner, though, got irritated by that unusual item on her finger. Coster, then, took it over and slipped it into the pocket of his waistcoat. The ring survived, but it was robbed from its diamond; the stone was used to further embellish an already overloaded other ring .... Vanity of vanities, all is vanity.

\section{Acknowledgment}

I am greatly obliged to Anne Meitner (Cambridge), daughter of Lotte Meitner-Graf, for helping to revive the past; to Athene Donald, Director of Churchill College, Cambridge, for permission to consult the papers of Lise Meitner; to Kristina Starkloff, Director, and Susanne Uebele of the Archives of the Max-Planck-Gesellschaft, Berlin; to Peter Prokop, Head of the Picture Collection of the Austrian National Library, Vienna; and to Rolf Siemssen (University of Groningen) for kind consultation.

\section{About the Author}

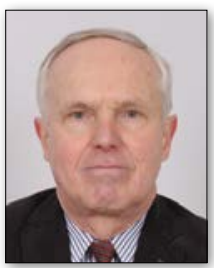

Henk Kubbinga is a historian of science at the University of Groningen and member of the EPS-HoP-Group. Actually he is finishing the fifth and last volume of The collected papers of Frits Zernike (1888-1966).

\section{References}

On Lise Meitner see Ruth L. Sime's excellent biography Lise Meitner. A life in physics, Berkeley etc.: University of California Press, 1998. For the broad context see Roger Stuewer, The age of innocence. Nuclear physics between the First and Second World Wars, Oxford: Oxford University Press, 2019.

[1] L. Meitner, Physikal. Z. 7, 588 (1906).

[2] O. v. Baeyer, O. Hahn and L. Meitner, Physik. Z. 12, 273 (1911).

[3] O. Hahn, Applied Radiochemistry, Ithaca (NY)-London: Cornell University Press, 1936.

[4] O. Hahn and L. Meitner, Physik. Z. 19, 208 (1918).

[5] L. Meitner and M. Delbrück, Der Aufbau der Atomkerne. Natürliche und künstliche Kernumwandlungen, Berlin: J. Springer, 1935. 